\title{
LA EDAD MEDIA EN LA EDAD DE ORO DEL SOFTWARE ESPAÑOL
}

Fran MATEU

Universidad de Alicante

\section{RESUMEN}

Desde sus inicios hasta la actualidad, los videojuegos han abarcado una miscelánea de géneros y temáticas que han permitido satisfacer los diferentes gustos de sus usuarios. Dentro de este conjunto general, encontramos las historias inspiradas en la Edad Media, pudiendo narrarse en un contexto histórico o como resultante de un híbrido de fantasía épica. En el texto se repasan algunos de los títulos más representativos circunscritos bajo este modelo, concretamente los desarrollados en España entre 1983 y 1992, un período conocido actualmente como la Edad de Oro del software español.

Palabras clave: Edad Media, fantasía épica, Edad de Oro, software español, videojuegos.

\section{ABSTRACT}

From its origins to the present, video games have covered a miscellany of genres and topics that have allowed to satisfy the different likes of its users. In this general set, we find the stories inspired by the Middle Ages, which can be narrated in a historical context or as a result of an epic fantasy hybrid. In the text, some of the most representative titles framed in this model are reviewed, specifically those developed in Spain between 1983 and 1992, a period known nowadays as the Golden Age of Spanish software.

Keywords: Middle Ages, epic fantasy, Golden Age, Spanish software, video games.

\section{INTRODUCCIÓN}

La Edad Media, como contexto histórico o como híbrido de fantasía épica, ha sido, desde sus orígenes, un elemento presente en multitud de obras artísticas. Este hecho, tan visitado en la industria del entretenimiento, está condicionado por los avances tecnológicos. En la actualidad, el público puede adquirir el último videojuego sobre el ciclo artúrico o visitar el Museo Nazionale del Bargello ${ }^{1}$ para contemplar al David de Donatello. Sin embargo, esta situación no sería recíproca para la población contemporánea a la primera exhibición del David, no sólo por los factores tecnológicos, sino también por los sociales, culturales y 
económicos. Es por ello que, en la actualidad, la democratización del consumo de productos de la industria cultural ha permitido que la población pueda consumir, en mayor o menor medida, obras de diversa índole tecnológica afines a sus intereses. En este sentido, la época medieval es un recurso altamente frecuentado a la hora de desarrollar obras artísticas en la era digital. Al tratar el Medievo en un sentido temporal, cabe citar al antropólogo Giuseppe Sergi: "Los límites cronológicos de la Edad Media más habituales en la tradición de los manuales son 476 [...] y 1492. [...] En todos los casos se reconoce generalmente como medieval al arco cronológico entre los siglos V y XV» (2001: 29). Por ello, la época medieval tiende a tratarse como una convención cronológica de acontecimientos sucedidos durante más de un milenio precedente al Renacimiento, distinguiéndose además entre la Alta Edad Media (del siglo $\mathrm{V}$ al X) y la Baja Edad Media (del siglo XI al XV), dos etapas comúnmente aceptadas por los historiadores, aunque siempre con variantes geográficas (Sergi, 2001: 2930).

Dentro del imaginario colectivo, el pensamiento medieval evoca una época oscura, sobre todo por los acontecimientos que tuvieron lugar (guerras, cruzadas, plagas, etc.). Además, se tiende a generalizar que la situación (alimentación, población, religión, feudalismo, etc.) fue siempre igual a lo largo de aquel largo período cuando, ciertamente, no lo fue (al igual que tampoco lo es en la actualidad). Dentro de este marco cronológico y de imaginario colectivo (generalizado e idealizado) cabe destacar dos conceptos que Sergi diferencia entre sí. El primero es el de Edad Media como «otro lugar» (negativo o positivo), y el segundo es el de Medievo como «premisa»:

En el otro lugar negativo hay pobreza, hambruna, peste, desorden político, abusos de los latifundistas contra los campesinos [...]. En el otro lugar positivo hay torneos, la vida de corte, elfos y hadas, caballeros fieles y príncipes magnánimos. Pero también es discutible el uso de la Edad Media como premisa genérica (de diversidad, o de preparación) de los siglos posteriores al XV (2010: 22-23).

Siguiendo esta división, se reconoce que la creación de obras artísticas bajo la instrumentalización del Medievo transita entre ambas vertientes. Haciendo hincapié en la primera de ellas, la Edad Media como «otro lugar», ambas posibilidades combinadas e idealizadas (lugar positivo y negativo), dan como fruto un híbrido de fantasía épica, popular subgénero dentro del fantástico cuyo sustrato o materia prima es la Edad Media², pero sin atenerse al rigor histórico, el cual sí es frecuente encontrar en obras ficcionales que contienen el Medievo únicamente como "otro lugar» negativo ${ }^{3}$, o en estudios en los que se trabaja como «premisa».

La fantasía épica ha generado un elevado volumen de productos culturales en cuyo contexto, de manera axiomática o más somera, quedan circunscritos los ecos medievales. En lo concerniente a los videojuegos, como indica el investigador Mateusz Sajna, la arquitectura de éstos contiene elementos como castillos o templos antiguos, y el usuario (haciendo uso, principalmente, de armas o hechizos) debe enfrentarse a enemigos que pueden ser más verosímiles, como bandidos ordinarios, o más afines al género fantástico, como dragones

2 Tan presente, por ejemplo, en los mundos de Tolkien, Eddison, Howard, Lewis, Moorcock, Frazetta, Achilleos, Le Guin, Hobb, Ende, Abercrombie o George R. R. Martin.

3 Como sucede en las novelas El nombre de la rosa (1980) o Baudolino (2000), ambas de Umberto Eco. 
o vampiros, dando lugar a un escenario medieval (o casi medieval) con condimentos de fantasía (2016: 45). Al igual que sucede en otras artes, los videojuegos medievales siempre han generado una gran atracción. Juan Francisco Jiménez Alcázar, de la Universidad de Murcia, señala lo siguiente:

Sobra decir que el videojuego inspirado o ambientado en la Edad Media, o simulándola, es uno de los grandes favoritos, tanto si es un juego que tiene una verosimilitud alta como si se trata de un mundo fantástico e irreal, vinculado a la imagen prototípica del Medievo (2009: 559).

Por ello, se reconoce la fascinación de un elevado número de usuarios por este tipo de videojuegos, a lo que Jiménez añade: «al fin y al cabo se trata de eso, de jugar, con todas las ventajas que el hecho lúdico colige para el fenómeno del aprendizaje y del acto educativo en sí, siempre desde la óptica de un medievalista y para la Historia Medieval» (2009: 552). En este sentido, el carácter pedagógico siempre ha estado presente en determinada tipología de videojuegos, pero en lo referente a la Historia Medieval se acentuó a partir de la década de 1990, siendo actualmente objeto de interés en el ámbito académico (Segura, 2017). Sin embargo, antes de que llegara la época actual, el usuario español tenía a su disposición otro tipo de títulos, entre cuyos objetivos no era tan frecuente encontrar el didáctico en un sentido histórico ${ }^{4}$, sino el de válvula de escape y divertimento. Eran videojuegos en cuyas historias también irrumpía la Edad Media y la fantasía épica, pixeladas en experiencias lúdicas de espada y brujería desarrolladas por firmas españolas como Dinamic, Opera Soft - Zigurat ${ }^{5}$ para microordenadores domésticos de 8 bits como el Sinclair ZX Spectrum ${ }^{6}$, el Amstrad CPC, el MSX o el Commodore 647 (Esteve, 2012a: 2). Aunque esta experiencia, aún desconocedora del sistema $\mathrm{PEG}^{8}$, no se hallaba sólo en los hogares, pues ya existían los salones recreativos, espacios públicos donde los usuarios encontraban software de diferente tipología?. Fue la época conocida como la Edad de Oro del software español.

Está comúnmente aceptado que la Edad de Oro del software español, término acuñado por la prensa especializada de la época ${ }^{10}$, tuvo lugar aproximadamente entre 1983 y 1992 (Relinque \& Fernández, 2015), y marcó un acontecimiento significativo derivado de la aparición de los primeros microordenadores domésticos y del desarrollo de videojuegos

4 Salvo en determinadas excepciones, buscando cierta veracidad o verosimilitud.

5 Además de otras desarrolladoras, distribuidoras y/o subsidiarias españolas de aquel período. No se entrará en detalles respecto a éstas, ya que, en muchas ocasiones, se trataba de la misma entidad al citar a dos diferentes, cuya nomenclatura cambiaba al modificarse parte de la plantilla de los programadores, tratándose de empresas en constante reestructuración, tanto dentro como fuera del circuito oficial.

6 Sucesor del Sinclair ZX81.

7 El Commodore 64 fue el microordenador menos vendido en España y para el que se desarrollaron menor cantidad de títulos (Perles, 2015).

8 Acrónimo de Pan European Game Information, código europeo de calificación de edad recomendada de los usuarios en base al contenido de los videojuegos, existente desde 2003 (Jiménez, 2009: 563).

9 Guillermo Tato apunta: «Durante los años setenta y ochenta un éxito en los salones recreativos generaba casi al instante decenas de copias que imitaban sin pudor alguno la jugabilidad del juego original. [...] Así que los salones recreativos se llenaban de juegos originales pero también de plagios de otros éxitos» (2016: 15).

10 La revista Micromanía realizó una retrospectiva en 1993 sobre lo que había significado el año 1987 para el videojuego en España, calificando aquel año como la Edad de Oro del software español (Esteve, 2012b: 15). Ejemplar actualmente disponible en <https://archive.org/stream/micromania-segunda-epoca-60/Micromania_ SE_60\#page/n0/mode/2up> [Última consulta: 17/04/2018]. 
para éstos. Francisco Portalo y Eduardo Mena apuntan: «Es la conjugación de estos dos factores [...] lo que marca la expansión de una nueva industria generalista basada en los programas informáticos, y los videojuegos resultaron un polo de atracción perfecto para su expansión» (2015: 101). Dentro de este contexto, es necesario citar Bugaboo (Indescomp, 1983), considerado tradicionalmente el primer videojuego español de la historia (Portalo, 2009: 5) ${ }^{11}$. Se trató, además, del primer título que generó cierta infraestructura industrial para todo lo que acontecería posteriormente, dando lugar a que se hablara por primera vez del software español, en un sentido comercial, fuera del país, sobre todo tras su éxito como número uno en Reino Unido (Relinque \& Fernández, 2015: 16). El desarrollo de videojuegos durante aquel período convirtió a España en uno de los países líderes en la industria del software (el segundo en Europa, por debajo de Reino Unido), apareciendo títulos tan conocidos como Fred (Indescomp, 1983), Abu Simbel, Profanation (Dinamic Software, 1985), Livingstone Supongo (Opera Soft, 1986) o Lorna (Topo Soft, 1990), entre muchos otros ${ }^{12}$. En aquel período también llegaron a España videojuegos extranjeros ${ }^{13}$ (gracias a firmas como Brøderbund Software, Atari o Imagine Software), generando una retroalimentación de importación y exportación constante, la cual permitió que aquella emergente industria española (a pesar de la también presente piratería), fuese en aumento hasta la llegada de los 16 bits en la década de 1990, sistema para el que no se adaptaron de manera considerable, dando lugar al ocaso de aquella etapa. Sin embargo, se trató de un período que, a pesar de que se pueda rememorar bajo la sospechosa mirada de la nostalgia, fue decisivo a nivel sociocultural y tecnológico en el tejido industrial español, dando lugar a videojuegos que han pasado a la historia bajo un reconocimiento internacional, destacando muchos de éstos por estar ambientados, precisamente, en la Edad Media.

\section{PRIMEROS VIDEOJUEGOS MÁS REPRESENTATIVOS}

La compilación de títulos ${ }^{14}$, sin el propósito de crear una base de datos que abarque su totalidad, se ha realizado en función de los principales referentes españoles del espacio lúdico, examinándolos bajo una perspectiva de análisis inductiva. Para realizar esta selección, que se presentará de manera cronológica por año de lanzamiento y alfabéticamente dentro de cada $a n ̃ o^{15}$ (independientemente de la importancia u oficialidad de la desarrolladora y del soporte), las principales referencias ${ }^{16}$ han sido las obras Ocho Quilates, una historia

11 También conocido como La Pulga, se considera el primer videojuego español, aunque aquel mismo año Japón comercializó Ambush (Tecfri, 1983), un arcade recreativo de origen catalán (Relinque \& Fernández, 2015 : 16).

12 Con portadas de ilustradores tan emblemáticos como Alfonso Azpiri, Juan Giménez, Carlos A. Díaz, Raúl López, Miguel Ángel Borreguero, Javier Cubedo, Ricardo Cancho o Luis Royo (Martínez del Vas, Ibáñez, Ortiz, Torres \& Saavedra, 2017: 168). Además de las populares ilustraciones de José María Ponce en la prensa especializada.

13 Además de software nacionalizado y conversiones españolas de títulos extranjeros (Relinque \& Fernández, 2015: 349-363).

14 Para realizar el compendio, se ha seguido el concepto medieval y la fantasía épica en un sentido argumental y estético, pero omitiendo obras cuyos argumentos (aunque estéticamente puedan evocar ligeramente al Medievo) giren en torno a distopías futuristas, salvo alguna excepción.

15 Al citarse alfabéticamente, los títulos no aparecen en función de su mes de salida al mercado dentro de cada año, realizándose además bajo el consenso de la bibliografía consultada, pues algunos títulos varían su año de aparición, dependiendo de la fuente.

16 Además de ZX Spectrum Book (Rolling, 2006) y The ZX Spectrum Book (Asadi, 2015). 
de la edad de oro del software español (I y II) (Esteve, 2012), Génesis: Guía esencial de los videojuegos españoles de 8bits (Relinque \& Fernández, 2015), la plataforma sobre videojuegos españoles Computer Emuzone ${ }^{17}$, fundada por José Luis Veiga Sierra, y World of Spectrum ${ }^{18}$, la principal base de datos electrónica de videojuegos para Spectrum, creada por Martijn van der Heide.

El primero ${ }^{19}$ de los títulos medievales españoles a citar es Yenght: La Fuente de la Juventud (Dinamic, 1984), cuyo protagonista debía encontrar aquella codiciada fuente, tratándose además del debut de Dinamic ${ }^{20}$ y de la primera aventura conversacional ${ }^{21}$ en español de la historia (Esteve, 2012a: 51). Durante el siguiente año apareció la videoaventura22 Camelot Warriors (Dinamic, 1985) (Fig. 1), inspirada en el ciclo artúrico, tratándose del primer videojuego con un sistema de protección antipiratería (Esteve, 2012a: 101-102). La desarrolladora incorporó el SD1, una pieza de hardware que el usuario debía colocar en el puerto de expansión (Relinque \& Fernández, 2015: 45). Otro de los videojuegos a citar es El Castillo de Godless (Idealogic, 1985)23, aventura conversacional donde el usuario controlaba al mago Azgar, haciendo uso de la magia y bajo una temprana arquitectura propia de la fantasía épica. Con Excalibur (Q.L.S., 1985), arcade ${ }^{24}$ centrado en la lucha en primera persona blandiendo espadas, se evidencia que el ciclo artúrico es una constante en los productos de la industria cultural, también presente en la Edad de Oro del videojuego español. Aquel mismo año salió a la venta un título programado íntegramente en catalán. Se trató de Guillem de Berguedá (ACE Software, 1985), una aventura conversacional inspirada en el trovador catalán del siglo XII que, como se indicaba en el propio videojuego, contó con el patrocinio de la Generalitat de Catalunya. Otro título fue La Princesa (Software Center, 1985), en cuya historia, en formato de puzzle, se debía rescatar a la princesa Annia Arrairs, hija del rey Satiar. Se trató de una obra anunciada como innovadora en cuanto a su desarrollo como aventura conversacional, pero su campaña publicitaria se alejaba en exceso del producto final (Relinque \& Fernández, 2015: 59). Fue en diciembre de aquel mismo año cuando apareció el arcade Sgrizam (Dinamic, 1985), un software diferente, en un sentido tecnológico, a todo lo que Dinamic había desarrollado hasta la fecha (Esteve, 2012a: 95). Aunque narraba una trama de ciencia ficción ${ }^{25}$, también se distinguían los ecos del Medievo como "otro lugar» positivo, con elementos tan particulares como castillos, princesas o dragones. El último de los videojuegos medievales más representativos de aquel año fue Sir Lancelot (OMK Software, 1985)²6, otro arcade de fantasía artúrica bajo una perspectiva isométrica ${ }^{27}$.

17 Disponible en <http://computeremuzone.com/> [Última consulta: 17/04/2018].

18 Disponible en <http://www.worldofspectrum.org/> [Última consulta: 17/04/2018].

19 De 1983, año inicial de la Edad de Oro, no se ha encontrado ningún título medieval relevante.

20 Una de las desarrolladoras de software más relevantes que hubo en España (Esteve, 2012a: 45).

21 Género lúdico donde el texto adquiere mayor relevancia, tanto para describirse las acciones, como para ejecutarlas el usuario.

22 Videojuegos de acción-aventuras.

23 Este título fue la única aventura conversacional de Idealogic (Relinque \& Fernández, 2015: 47).

24 El término arcade suele aplicarse a videojuegos de mucha acción y jugabilidad, relacionándose, por ejemplo, con géneros deportivos, de plataformas o de disparos (shooters).

25 Una de las pocas excepciones bajo este paradigma dentro del compendio.

26 También conocido como Sir Perceval (Relinque \& Fernández, 2015:63).

27 Visión tridimensional en dos dimensiones, jugando con una perspectiva en angulación picada y 3/4. 


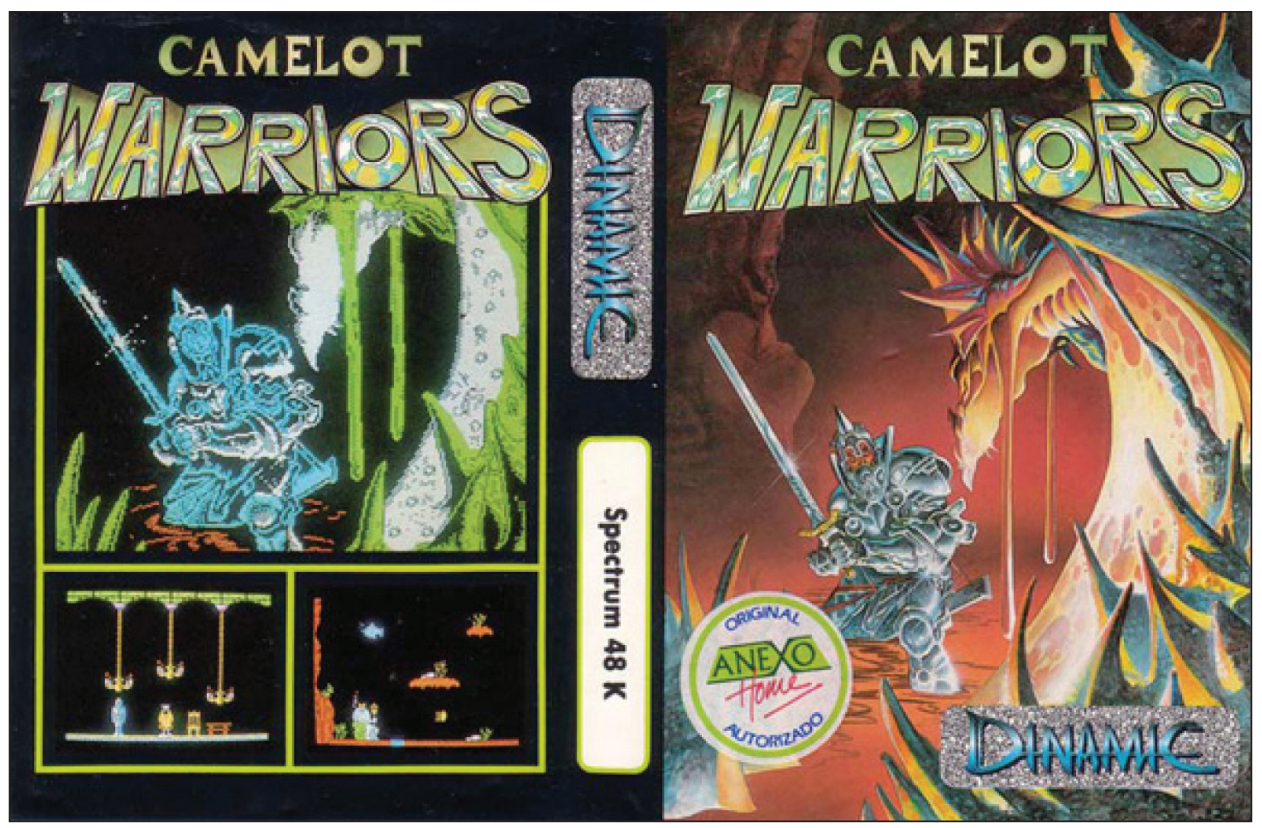

Figura 1: Portada y contraportada de Camelot Warriors

(Dinamic \& Opera Soft, 1985), con ilustración de Alfonso Azpiri.

Fuente: <http://spectrumforever.speccy.org/index.html>

[consulta: 17 abril 2018].

\section{DURANTE EL CENIT DE LA EDAD DE ORO}

A partir de 1986, el software español de temática medieval empezó a cobrar mayor protagonismo, máxime por su salida al mercado a través de nuevas desarrolladoras ${ }^{28}$, permitiendo refrendar la notoriedad de dicho eje temático en la Edad de Oro. Cabe señalar que Drácula (GTS \& Génesis, 1986) no fue una videoaventura ambientada en el Medievo, pero este temprano relato vampírico contuvo elementos circunscritos dentro de éste (que tiende a compartir con el goticismo arquitectónico), por lo que se ha incluido dentro de esta compilación. Manteniendo la idea arquitectónica, también conviene citar El Castillo Embrujado (Microhobby, 1986), arcade que acomodaba la fantasía épica bajo un magma inherente que contaba con la presencia de la magia y la alquimia. Por otro lado, dado que los límites cronológicos de la Edad Media se acotan desde la caída del Imperio Romano de Occidente hasta la llegada de Colón a América en 1492 (Sergi, 2001: 29), es necesario mencionar la videoaventura El Descubrimiento de América (OMK Software, 1986) ${ }^{29}$. Se trató de un videojuego enmarcado en el Medievo, en un sentido histórico y con cierto carácter didáctico, en el que Colón, junto al resto de su tripulación, debía partir a Las Indias. Retomando la época medieval como "otro lugar» positivo, aquel año también apareció King Leonard (Mind Games, 1986), arcade ambientado en el siglo XII (Baja Edad Media), en el que el rey Leonard, traicionado por su hermano, debía recorrer un castillo plagado de seres encantados para recuperar un tesoro. Bajo el mismo trazo, también encontramos La Maldición de Jarak (Sygran, 1986), cuyo protagonista sobrevivía a través de las pócimas que debía conseguir recorriendo una pixelada fortaleza. Por otra parte, cabe destacar la

28 Como las populares Opera Soft y Made in Spain (de la que derivaría Zigurat, pues eran entidades en constante cambio), o la desarrolladora y distribuidora Erbe Software.

29 Considerado el título más notable de OMK Software (Relinque \& Fernández, 2015: 78).

Quaderns, 13 (2018), pp. 63-84 
aparición del arcade de plataformas Las Tres Luces de Glaurung (Erbe Software, 1986) ${ }^{30}$, uno de los títulos más representativos de aquel momento, llevado a cabo por parte del equipo que formaría la futura Topo Soft (Esteve, 2012b: 71). Bajo la disposición del mapa de un castillo y siguiendo la mirada de la Edad Media como "otro lugar» positivo, el usuario manejaba al caballero Redhan, que debía hacerse con tres joyas (protegidas por el brujo Kulwoor y el dragón Glaurung ${ }^{31}$ ), las cuales le darían el poder necesario para recuperar los territorios de Taleria. También cabe mencionar la videoaventura Nonamed (Dinamic, 1986), que entremezclaba la fantasía épica con el humor, recorriéndose nuevamente un castillo en el que se debía derrotar a un dragón. Este popular videojuego recibió aquel título al no dar con un nombre adecuado para éste (Relinque \& Fernández, 2015: 91). Del mismo género, también apareció Robin (Indescomp, 1986), software inspirado en el héroe del folclore inglés donde el usuario transitaba por espacios propios de la fantasía épica (castillos, catacumbas, etc.), blandiendo una espada para sortear a los diferentes enemigos. Otra obra que salió a la venta aquel año fue Rocman (Magic Team, 1986), videojuego de plataformas donde el usuario, únicamente con tres vidas a su disposición, debía superar diversos obstáculos en su camino hacia la búsqueda del Grial. Llegados a este punto, nos encontramos ante la aparición de Sir Fred (Made in Spain, 1986), otro de los títulos que supuso un gran éxito ${ }^{32}$ en aquella edad dorada. En esta videoaventura de fantasía épica, el protagonista recorría una fortaleza para rescatar a una princesa ${ }^{33}$. Supuso un avance en la programación, sobre todo por la jugabilidad del personaje (en cuanto a inercia y sistema de control), además de las aportaciones del programador Paco Menéndez, junto al resto del equipo, en su desarrollo (Esteve, 2012a:105). En este sentido, los programadores dotaron al personaje de una amplia gama de habilidades, siendo uno de los primeros títulos españoles que incluyó aquellas innovaciones, unidas a la aleatoriedad de aparición de sprites ${ }^{34}$ en el mapeado del software (Rollings, 2006: 171). Por último, aquel año también apareció Thor y la Cría de Dragón (GTS, 1986), un arcade con tintes de mitología nórdica en el que se respiraba la fantasía épica a través de una arquitectura cavernosa junto a una variedad de enemigos con la presencia antagónica, nuevamente, de otro dragón.

Un año más tarde, el software español se hizo eco de dos figuras clásicas del Medievo ibérico. Por una parte, la adaptación de la obra más representativa de Cervantes se materializó a través de la aventura conversacional Don Quijote (Dinamic, 1987) ${ }^{35}$. Aunque no esté enmarcada estrictamente en la Edad Media, su conexión temática, fruto de la locura del protagonista a raíz de leer libros de caballería, hace ineludible que sea citada (Asadi, 2015: 93). El segundo título fue El Cid (Dro Soft \& Juliet Software, 1987), un arcade isométrico ambientado en la Baja Edad Media e inspirado en la conocida figura histórica del vasallo castellano Don Rodrigo Díaz de Vivar que, curiosamente, tuvo mejor acogida fuera de España (Esteve, 2014: 88). Siguiendo la misma huella medieval, dentro de aquel

30 En Reino Unido fue distribuido por Melbourne House bajo el título Conquestador, recibiendo muy buenas críticas (Relinque \& Fernández, 2015: 105).

31 Glaurung también fue el nombre de otro dragón, presente en la Tierra Media de Tolkien.

32 El éxito de este título permitió que sus creadores formaran una nueva desarrolladora y distribuidora de software, dando lugar al nacimiento de Zigurat (Esteve, 2012a: 110).

33 Con un estilo visual que recordaba a las ilustraciones del dibujante argentino Guillermo Mordillo.

34 Término que hace alusión a los gráficos móviles de un videojuego.

35 El propio nombre de Miguel de Cervantes apareció en los créditos del videojuego como guionista, y fue un título elogiado por la prensa especializada de la época (Esteve, 2012b: 63). 
año también apareció El Cruzado (Nuevo Soft Español, 1987), una aventura conversacional sobre un caballero que había regresado de las Cruzadas y era atacado en la entrada de su reino. Regresando a la fantasía épica, otro de los títulos que salió a la venta fue Fredy (GTS, 1987), un arcade cuyo protagonista debía sortear los distintos obstáculos de un castillo. Con la llegada de Gorbaf el Vikingo (Magic Team, 1987), regresamos a la mitología nórdica a través de un arcade de perspectiva cenital forzada ${ }^{36}$, estilo muy recurrente en aquella época. El vikingo protagonista utilizaba una magia, que paralizaba momentáneamente a sus enemigos, mientras trataba de conseguir las diferentes llaves que le permitían superar cada nivel. En la aventura conversacional Historias de Medialand (JSJ Soft, 1987), un hechicero había esclavizado a los aldeanos de Medialand, y el usuario debía rescatarlos superando diferentes obstáculos y una variada tipología de enemigos tradicionales de la fantasía épica, como trolls, orcos o crías de dragón. Otra de las obras, circunscrita bajo una temática similar, fue Knight Ghost (Juliet Software, 1987), un videojuego de plataformas cuyo personaje debía recorrer el interior de un castillo, sorteando los diferentes obstáculos. Se puede evidenciar que en la experiencia lúdica medieval se cumplía, en mayor o menor medida, cierta constante en cuanto a arquitectura, trama y tipología de personajes. Sin embargo, un acontecimiento de especial importancia sucedió aquel mismo año, haciendo que el usuario español se enfrentara ante un título tan célebre como insólito, marcando un antes y un después en el software español. Por ello, es relevante hacer un alto en el camino, poniendo el foco de atención sobre la aparición de La Abadía del Crimen (Opera Soft, 1987) (Fig. 2). Se trató de la adaptación no oficial de la novela El Nombre de la Rosa (Eco, 1980), pues los desarrolladores no llegaron a conseguir los derechos (Esteve, 2012b:97). Esta aventura isométrica, realizada por el programador Paco Menéndez y el arquitecto Juan Delcán, no se distribuyó fuera de España, lo cual no impidió que marcara un hito generacional, junto con la aparición de remakes posteriores (Esteve, 2014: 112). Además, tampoco tuvo un impacto relativamente alto cuando llegó al mercado, pero con el paso del tiempo se convirtió en un videojuego de culto $^{37}$ (Esteve, 2014: 7-8). Su singularidad se basó, sobre todo, en su compleja jugabilidad ${ }^{38}$ y en la maximización de todos los recursos para compactar el videojuego todo lo posible ${ }^{39}$, dando lugar a mayor rapidez de carga junto a unos gráficos que asombraron a la prensa especializada (Esteve, 2014: 70). Todo ello sumado al resultado estético de los escenarios, configurados por Juan Delcán, cuya isometría jugó una doble vertiente, contextualizando al usuario en aquella Baja Edad Media, y desorientándolo a través de los recovecos de aquel recinto eclesiástico (Esteve, 2014: 45). Con este título, el usuario se hallaba, al igual que sucedía con la novela, en un contexto ambientado en el siglo XIV, pero con la mirada hacia "otro lugar» negativo, donde el desorden político, religioso y social giraba en torno a la laberíntica abadía en la que tenía lugar la historia. Al igual que sucedía en la obra de Eco, los protagonistas del videojuego también eran Guillermo de Baskerville (renombrado como Guillermo de $\mathrm{Occam}^{40}$ ) y el novicio Adso de Melk (cuyo apellido no se llegaba a citar). Del mismo modo, el argumento se centraba en averiguar quién era el culpable de los asesinatos

36 Aunque el espacio fuese visto desde arriba, los personajes se veían de manera frontal a nuestra mirada. 37 Al igual que sucedió con Sir Fred (Made in Spain, 1986), fue un software adelantado a su época.

38 Las pantallas isométricas que iban apareciendo (al pasar de una sala a la siguiente) también modificaban el ángulo de visión, provocando cierta desorientación en el jugador (Esteve, 2014: 103).

39 En menos de 128 kilobytes de memoria (1024 kilobytes equivalen a 1 megabyte).

40 Personaje histórico (vinculado al empirismo y al nominalismo) con el que Guillermo de Baskerville mantiene amistad en la novela (Eco, 1980: 23). 
que estaban sucediendo en la abadía, cuya trama se desarrollaba en siete días (al igual que en la novela) mientras que, paralelamente, se tenían que cumplir las órdenes del Abad. Se trató de un videojuego que, desde su propio intertexto y su cualidad novedosa, originó una revolución en el software español, además de un caso excepcional dentro de éste, convirtiéndose en el primer título español que alcanzó el prestigio internacional (Avellaneda, 2002). Por todo ello, actualmente se considera el máximo exponente de la calidad que podía ofrecer el software español en aquella época (Relinque \& Fernández, 2015: 111). Además, aquel año se cerraría con cuatro títulos medievales más. Regresando a las leyendas artúricas, uno de ellos fue Merlin (Mind Games, 1987), un arcade de desplazamiento ${ }^{41}$ lateral en el que el usuario debía conseguir diferentes elementos de la tabla periódica para que las pócimas de Merlín llegaran a buen término. En este sentido, fue un software en el que el entretenimiento del usuario era un subterfugio digital para desarrollar un segundo objetivo didáctico. Del mismo género, y también bajo la mirada artúrica, el siguiente videojuego fue Sir Camelot (Sygran, 1987), que en este caso, y como contrapunto, su tratamiento consistía en el avance y la lucha del personaje en primera persona. La videoaventura Spirits (Topo Soft, 1987) también tuvo cierta notoriedad. La pantalla se dividía en dos segmentos, viendo al mago protagonista en la superior y las distintas partes del castillo en la inferior, siendo este esquema un elemento diferenciador respecto al resto de títulos de aquel momento (Relinque \& Fernández, 2015: 144-145). El último título medieval de aquel año fue Talismán (Unicornio Soft \& A.G.D., 1987), un videojuego de plataformas cuya estética rememoraba la tan visitada fantasía épica.

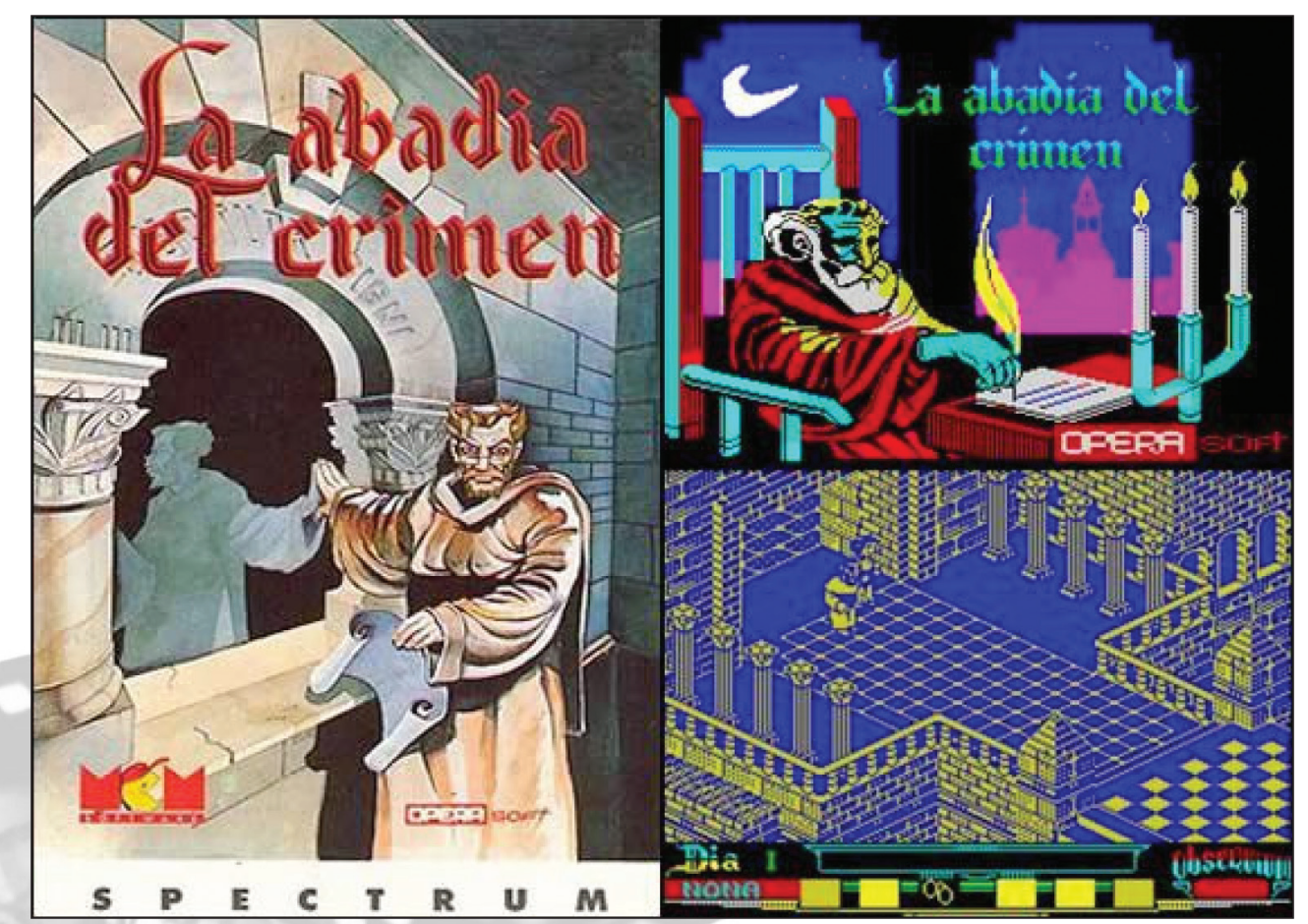

Figura 2: Portada de La Abadía del Crimen (Opera Soft, 1987), con ilustración de Juan Delcán, y dos imágenes del videojuego. Fuente: <https://www.pixfans.com/remakes-espanoles-vol-i/> [consulta: 17 abril 2018].

41 En el argot de los videojuegos, al desplazamiento también se le conoce como scroll. 
La aventura conversacional Abracadabra (Proein Soft Line, 1988) dio inicio a los títulos españoles circunscritos al Medievo que salieron a la venta un año después. En ella, el protagonista Clus d'Elford, caballero de la Orden de Dottersen, debía combatir contra enemigos del "otro lugar» positivo (dragones, demonios, etc.) a través del castillo de Bungerfels. Todo ello para salvar a la princesa Violeta, manteniéndose cierta constante argumental en esta tipología de experiencias lúdicas. Por otro lado, el arcade Arkos (Zigurat, 1988) adentraba al usuario en una trama de fantasía épica en la que debía recuperar el hacha de Grix, robada por el alquimista Tarox, para devolverla a la aldea de Kartes. A este título le siguió Atrog (Zafiro Software, 1988), un beat 'em up ${ }^{42}$ ambientado en un contexto vikingo. Situado en el período medieval, y con tintes fantasmagóricos, aquel año también apareció Crusader (System 4, 1988), un arcade isométrico que, debido a su interfaz, sólo estuvo disponible para Spectrum (Relinque \& Fernández, 2015: 166). A continuación, con la videoaventura de plataformas Dea Tenebrarum (System 4, 1988), el usuario se puso el hábito para controlar a un monje que disponía de una magia paralizante con la que combatía a sus enemigos, contando con la presencia de demonios y otro tipo de criaturas propias de la fantasía épica. Regresando a la espada y brujería de mitología nórdica, la videoaventura Hundra (Dinamic, 1988) ${ }^{43}$ contaba la historia de una vikinga que debía encontrar tres gemas sagradas (Fig. 3). En su trama se citaban a Jorund, rey de los Vikingos del Norte, y al dios Loki. A continuación, en la aventura conversacional La Corona (System 4, 1988) ${ }^{44}$, el protagonista, con el objetivo de convertirse en rey, debía recorrer un desierto hasta llegar a un castillo al final de éste. Con Leyendas (Mind Games, 1988), el usuario debía enfrentarse a otra aventura conversacional de fantasía épica. Por otro lado, con Mega Chess (Genesis Soft, 1988) ${ }^{45}$ accedíamos al mundo del ajedrez. El juego de mesa a través del píxel tenía un objetivo claro, pero la estética y la presentación del software condujeron a que en éste resonaran ciertos ecos de la Edad Media. Los siete últimos títulos a mencionar de aquel sustancioso año son Silphy (lber Software, 1988), arcade en el que un hada ${ }^{46}$ debía recuperar las cajas del saber; Starlife (Zafiro Software, 1988), aventura conversacional con reminiscencias de la fantasía épica; Temptations (Topo Soft, 1988), videoaventura cuyo protagonista era un monje medieval; Thanos (Microhobby, 1988), arcade en el que un arquero debía combatir contra diversos enemigos; Thor (Proein Soft Line, 1988), software de plataformas en el que el usuario se sumergía, una vez más, en el mundo vikingo; Tuareg (Topo Soft, 1988), videoaventura de compleja jugabilidad; y Zhak (Microhobby \& Legio Soft, 1988), título en el que el usuario debía recuperar tres objetos mágicos adentrándose en el castillo de Manghor, antagonista de la historia.

42 Género lúdico basado en el combate cuerpo contra un elevado número de antagonistas.

43 Se trató de la adaptación de la película homónima dirigida por Matt Cimber (Esteve, 2012b:152).

44 Este título es especialmente recordado debido a que fue programado por Pedro Amador López cuando contaba únicamente con 13 años de edad (Relinque \& Fernández, 2015:165).

45 La adaptación no oficial de Super Chess (Kuma Computers, 1984) (Relinque \& Fernández, 2015:363).

46 Personaje arquetípico de la fantasía épica, siendo este título la adaptación no oficial de Elidon (Orpheus, 1985) (Relinque \& Fernández, 2015:363). 


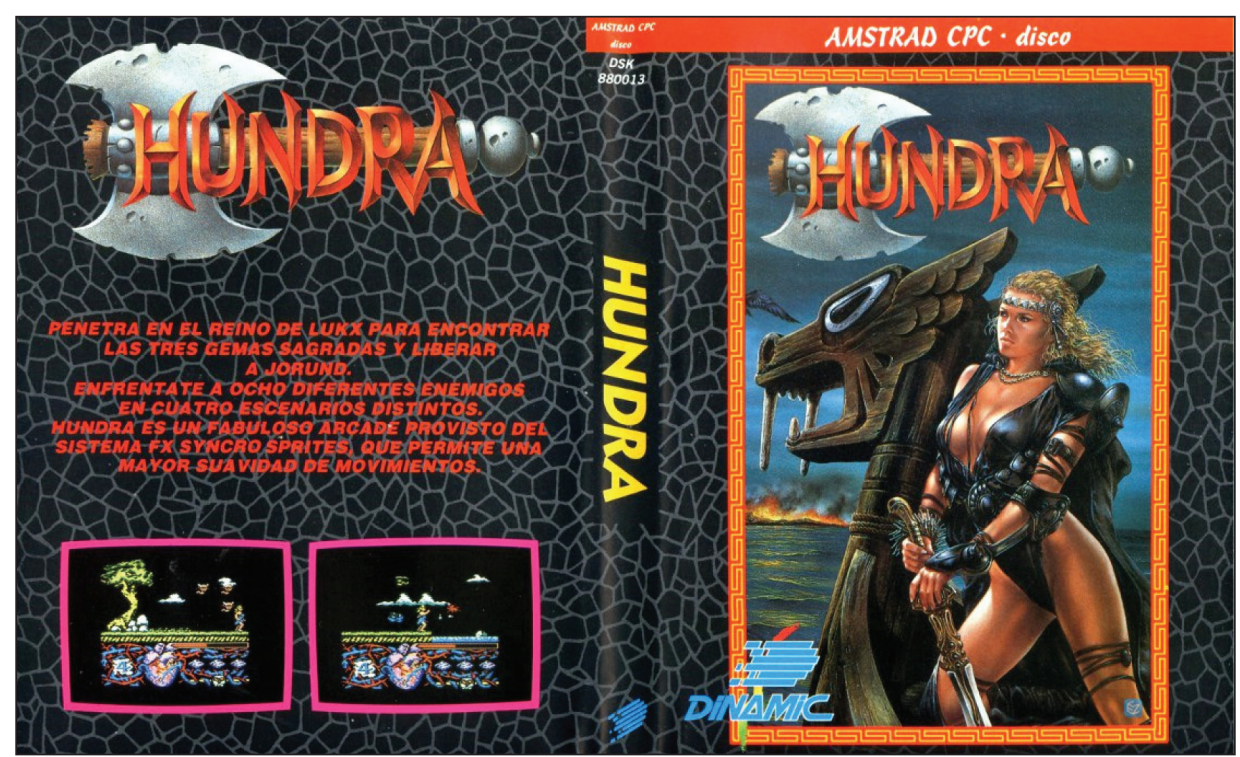

Figura 3: Portada y contraportada de Hundra (Dinamic, 1988),

con ilustración de Luis Royo. Fuente: <http://computeremuzone.com/ficha.php?id=523> [consulta: 17 abril 2018].

Siguiendo la misma impronta nórdica, y con elementos de ciencia ficción, el arcade de plataformas Drakkar (Delta Software \& Diabolic, 1989) es el primero de los títulos a citar que aparecieron un año más tarde. Su trama giraba en torno al joven Erik, un vikingo que debía viajar en el tiempo para arrebatarles a los romanos los laureles del César, los pergaminos de la sabiduría y el trofeo de la guerra. Regresando a las figuras clásicas del Medievo ibérico como «otro lugar» positivo, aquel año fue el turno para la videoaventura El Capitán Trueno (Dinamic, 1989), un arcade que pasó ligeramente desapercibido en el ámbito publicitario (Esteve, 2012b: 211-212). No obstante, tuvo buena acogida por parte de los usuarios al contener, en términos de calidad, los elementos más característicos de su desarrolladora (Asadi, 2015: 93). Adaptando el tebeo de Bruguera, el Capitán Trueno debía acabar con la maldición que había caído sobre el Abad Estanislao de Castiglione, el cual se había transformado en una extraña criatura. Además de ponerse bajo la piel del caballero cruzado, el usuario también manejaba a los otros dos protagonistas del clásico tebeo, Crispín y Goliath, programándose de tal manera que se podía controlar a un personaje u otro en función de la tarea a realizar (Relinque \& Fernández, 2015: 240). Por otro lado, con El Señor del Dragón (Creators Union, 1989), el usuario se adentraba en un software de fantasía épica donde debía conseguir controlar a un dragón volador y, posteriormente, liberar a un reino de la amenaza del Rey de lo Oscuro. A este título le siguió Enchanted (Positive, 1989), un videojuego de pinball cuya presentación también condujo a que mantuviera cierta estética de fantasía épica, con la figura de un mago que controlaba los engranajes de aquellas partidas. En el caso de Guillermo Tell (Opera Soft, 1989) (Fig. 4), el usuario debía tomar el rol del protector del protagonista (inspirado en el legendario ballestero suizo), defendiéndolo del ataque de sus enemigos. Este componente convirtió a dicho arcade en una experiencia lúdica diferente, ya que lo habitual era que el usuario controlara al propio protagonista, en lugar de defenderlo ${ }^{47}$.

47 Curiosamente, en la contraportada del videojuego se le preguntaba al potencial usuario si quería ser Guillermo Tell. 


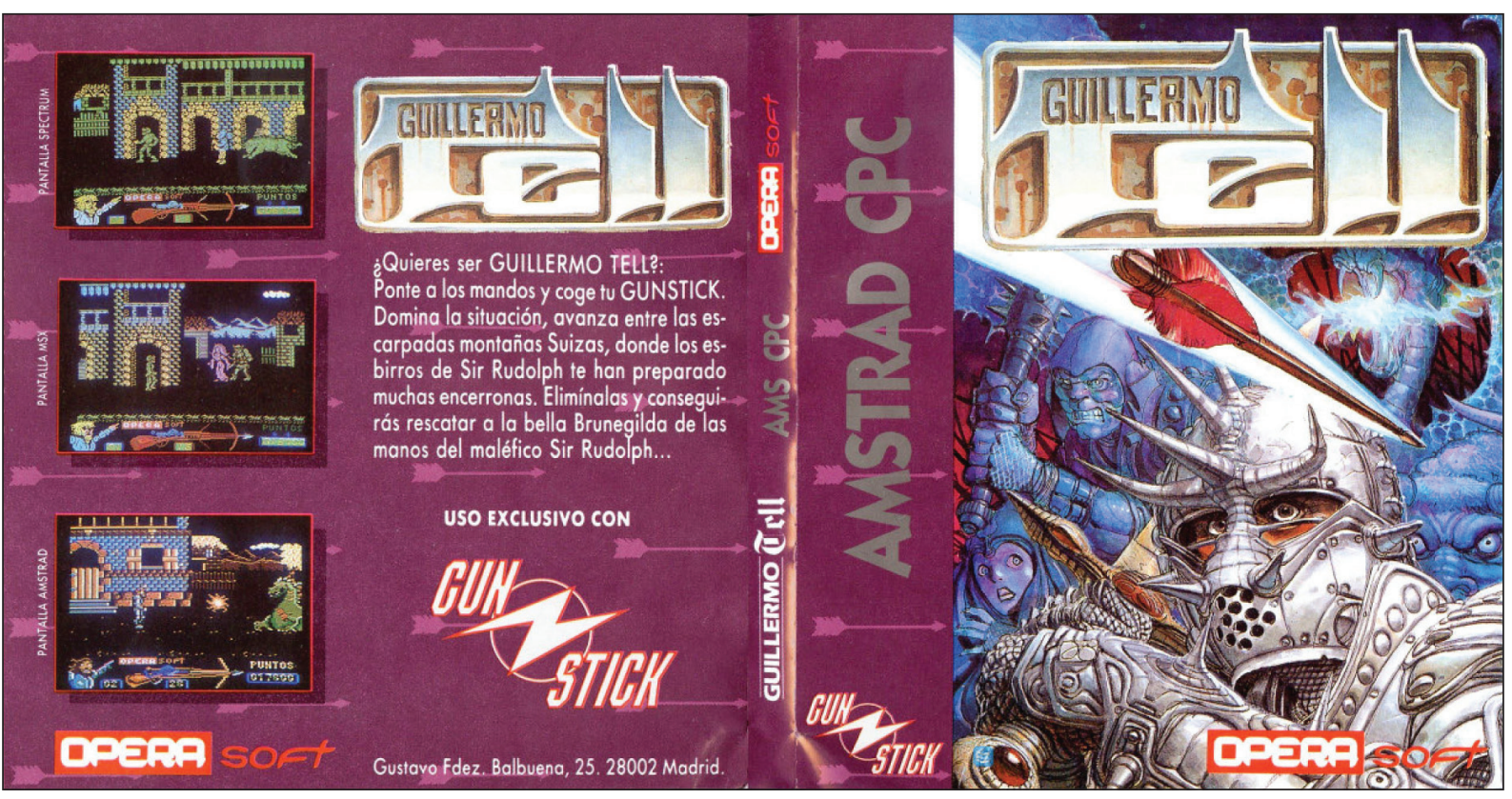

Figura 4: Portada y contraportada de Guillermo Tell (Opera Soft, 1989), con ilustración de Juan Giménez. Fuente: <http://spectrumforever.speccy.org/index.html> [consulta: 17 abril 2018].

Por otro lado, la videoaventura Khazzad-Dum (System 4, 1989) tuvo una notable influencia del universo de Tolkien, lo cual ya quedaba patente en el propio título ${ }^{48}$. Bajo la misma mirada de la fantasía épica, también salió a la venta Krom: El Guerrero Invencible (OMK Software, 1989) ${ }^{49}$, un arcade en el que un guerrero debía combatir contra los diferentes obstáculos que aparecían ante él mientras recorría diversos pasadizos. Otro de los títulos ambientados en la Edad Media que formaron parte de aquel año fue La Aventura Original (Aventuras $A D, 1989)$. Se trató de una aventura conversacional en la que había que acceder al interior de una cueva, conseguir diversos tesoros, y salir del lugar antes de que se derrumbara. Todo ello con tintes de fantasía épica y a través de un software que tuvo buena repercusión por parte de los usuarios (Esteve, 2012b: 220). Por otro lado, con Pueblo de la Noche (Creators Union, 1989), el usuario, acompañado de una valkiria ${ }^{50}$, se enfrentaba a otra aventura conversacional en la que aparecían personajes propios de la fantasía épica, como magos, brujas, espectros o duendes. El último de los títulos a citar de aquel año es Satan (Dinamic, 1989), otro software de fantasía épica en el que el propio personaje evolucionaba de guerrero a mago a través de la propia historia.

\section{HACIA LA DECADENCIA Y FIN DE LA EDAD DE ORO}

Con la llegada de 1990, la crisis del software español empezaba a fraguarse. Sin embargo, varios títulos de temática medieval aparecieron a lo largo de aquel año, el cual dio inicio a una década que pondría fin a aquel período dorado. El primero de ellos

48 En la obra de Tolkien, las minas de Moria también se conocen como Khazad-dûm.

49 Su apartado gráfico fue lo que más llamó la atención, inspirado ligeramente en las pinturas de la Grecia clásica (Relinque \& Fernández, 2015: 262).

50 Entidad femenina de la mitología nórdica.

Quaderns, 13 (2018), pp. 63-84 
fue La Corona Mágica (OMK Software, 1990), un arcade de scroll lateral con tintes de magia y fantasía inspirado en la serie homónima de animación que se emitió en España durante aquella época (Relinque \& Fernández, 2015: 297). A continuación, en La Cueva del Dragón (Manali, 1990), un caballero debía recuperar los tesoros que un dragón custodiaba en su guarida a través de un arcade cuya premisa también recordaba a los mundos de Tolkien. Por otro lado, encontramos La Espada Sagrada (Topo Soft, 1990), una mezcla de videoaventura y arcade en la que su protagonista debía conseguir aquella espada a lo largo de tres fases. Con la fantasía épica de Legend (Delta Software, 1990), el usuario se hallaba ante una aventura conversacional en la que tres jóvenes (Crux, Kyra y Dunha), debían enfrentarse a diferentes peligros hasta llegar a Krull, el antagonista de la historia. Aquel año también apareció Mithos (Opera Soft, 1990), un arcade que combinaba la mitología griega con la fantasía épica a través de un centauro que recorría el scroll lateral con, únicamente, tres vidas a su disposición. La llegada de Power Magic (Zigurat, 1990) condujo a la recuperación del ciclo artúrico de manera intertextual, pues era el hijo de Merlín el que debía recorrer distintos lugares enfrentándose, en formato de beat 'em up, a los diferentes adversarios que iban apareciendo. El último software medieval de aquel año fue la videoaventura Sirwood (Opera Soft, 1990), cuya historia narraba la leyenda de un escudo dorado que protegía a los habitantes de Nargoort y había sido robado por el mago Amargol. El usuario, bajo la piel del pastor Arn Sirwood, debía emprender la búsqueda de aquel valioso objeto.

En el año 1991, el software español entró en su crepúsculo, y la mayoría de los títulos citados formaron parte de un circuito menos oficial. De aquel año cabe mencionar la aventura conversacional Akbarr (Ardent Software, 1991), en la que el usuario transitaba por lugares en los que descubría a personajes característicos de la fantasía épica, como magos o enanos. A este título le siguió El Señor de los Anillos (Dimassoft, 1991), otro software del mismo género que el anterior, el cual adaptaba el primer volumen de la trilogía homónima de Tolkien. A continuación, cabe destacar Genghis Khan (Positive, 1991), videojuego ${ }^{51}$ dentro del circuito oficial inspirado en la figura del conquistador mongol, cuyo objetivo era llegar a la ciudad de Bagdag, en la que un alquimista le revelaba al guerrero qué cinco ingredientes necesitaba para poder fabricar pólvora. Una vez conocidos, el guerrero debía conquistar los territorios en los que se encontraban dichos elementos para, posteriormente, derribar la Gran Muralla China y destruir la ciudad de Pekín. Los tres últimos títulos a mencionar de aquel año, que compartieron el género de la aventura conversacional, son Guillermo Idiliar Dambor (Creators Union, 1991), donde había que viajar a la fortaleza de Miriador para liberarla; La Liberación de Silvania (Aventuras FJAP, 1991), donde se debía recuperar la paz del pueblo de la Montaña de Plata; y The Last Warrior (Iron Chip, 1991), otro software que visitaba de nuevo la fantasía épica.

De los videojuegos desarrollados en 1992, emplazados bajo el sustrato del Medievo, es necesario citar dos títulos. Por un lado, Risky Woods (Dinamic \& Zeus Software, 1992), un arcade de plataformas circunscrito a la fantasía épica donde el usuario debía rescatar a diversos monjes petrificados mientras iba superando diferentes niveles. Esta obra, inicialmente publicada para Atari ST, Amiga y MS-DOS, fue determinante, pues su éxito hizo que se adaptara para Sega Mega Drive $^{52}$, siendo el primer videojuego español que

51 En función de cómo se configurara, el género podía ser arcade, estrategia o ambos.

52 Adaptándolo a 16 bits, como cualidad novedosa, y bajo la distribución internacional de Electronic Arts. 
apareció en una videoconsola, además de representar el último título de Dinamic y el fin de la Edad de Oro (Alonso, 2017). El otro título que cabe citar es The Prayer of the Warrior (Zigurat, 1992), un videojuego de fantasía épica, con un elaborado apartado gráfico, que en su momento no llegó a ver la luz ${ }^{53}$. Su publicación se planteó para 1992, pero no se llevó a cabo por la recesión económica de inicios de la década de 1990 (Esteve, 2012b: 279).

En definitiva, nos encontrábamos ante el final de la actualmente conocida Edad de Oro del software español. Lo que sucedió con los títulos medievales, cuya salida al mercado experimentó su auge y decadencia en aquel período, se podía extrapolar al resto de géneros. En lo referente al final de aquella edad dorada, hay que tener en cuenta el advenimiento del hardware de 16 bits, cuyo software era más costoso de realizar y exigía un sistema de trabajo que en el tejido industrial español no se pudo llevar a cabo en condiciones suficientemente competitivas ${ }^{54}$. Por ello, el mercado interno se colapsó, ya que, además, el nuevo software era más sencillo de piratear ${ }^{55}$. A ello, cabe añadir que las empresas españolas continuaron desarrollando software de 8 bits, lo cual las condujo a ser poseedoras de una tecnología cada vez más obsoleta (Esteve, 2012b: 306-307). El problema básico era que el coste para desarrollar un videojuego español de 16 bits no se podía amortizar. Además, ya no se consumía tanto software de 8 bits, y el mercado español de 16 bits estaba colmado de títulos extranjeros pero, en gran medida, a través de copias pirateadas. Sin añadir más variables sobre las causas del fin de la edad dorada, es conveniente tener presente que el lanzamiento de títulos españoles se redujo drásticamente y con precios muy bajos. Por ende, aquello impedía el crecimiento económico, imposibilitándose la recuperación del nivel que se había vivido años atrás. No obstante, los videojuegos que aparecieron durante aquel período dorado enriquecieron la experiencia lúdica, y el volumen de títulos españoles enmarcados en la Edad Media fue notable ${ }^{56}$.

\section{VIDEOJUEGOS DESARROLLADOS FUERA DE ESPAÑA}

Por otro lado, en aquellos años también afloró un elevado número ${ }^{57}$ de videojuegos extranjeros que ampliaron, en gran medida, la experiencia lúdica medieval. Encontramos precursores $^{58}$ internacionales, como Dungeons \& Dragons (Gary Whisenhunt \& Ray Wood,

53 Actualmente disponible en <http://www.worldofspectrum.org/infoseekid.cgi?id=0014425> [Última consulta: 17/04/2018].

54 Un videojuego de 8 bits se podía hacer con un equipo muy reducido, pero la llegada de los 16 bits implicaba un nuevo modelo de profesionalización (Martínez del Vas et al., 2017: 34).

55 Como indica Jaume Esteve: «Si hacer una copia de un juego de 8 bits en casete provocaba copias imperfectas fruto del propio soporte, la llegada de las unidades de disco permitió, ahora sí, tener juegos calcados al original en cuestión de segundos» (2012b: 306).

56 Según la prensa especializada, varios de los videojuegos españoles más destacados forman parte de la Edad de Oro, siendo algunos de éstos de temática medieval (Alonso, 2017).

57 Durante la redacción del presente texto, la compilación transversal realizada de videojuegos extranjeros medievales desarrollados hasta 1992 (teniendo en cuenta varios precursores), asciende a más de 300 títulos. Para realizar esta selección (de la que sólo se mencionará alguna obra en particular), además de las fuentes ya señaladas, también se ha consultado The History of ZX Spectrum in Pixels (Wilkins, 2014) y The CRPG Book Project. Sharing the History of Computer Role-Playing Games (Pepe, 2018).

58 Debido a la tecnología de la época, en los títulos más tempranos la Edad Media quedaba reflejada de forma más somera, básicamente en el packaging y en la pantalla inicial del software. 
1975), Colossal Cave Adventure (William Crowther \& Don Woods, 1976)59 o Adventure (Atari, 1979), considerado el primer software de aventuras, además del primer videojuego que escondía un huevo de pascua ${ }^{60}$, pues su programador, Warren Robinett, ocultó su nombre en una de las pantallas, haciéndolo en una época en la que Atari no permitía que sus programadores aparecieran en los créditos (Crespo, 2010: 29-30). Posteriormente surgieron títulos como Ultima I: The First Age of Darkness (Richard Garriott, 1981) o Wizardry: Proving Grounds of the Mad Overlord (Sir-Tech, 1981), iniciándose sagas que captaron cada vez mayor atención. Otro videojuego popular de aquel período fue Dragon's Lair (Advanced Microcomputer Systems, 1983), donde el caballero Dirk debía rescatar a la princesa Daphne de las garras de un dragón. Tuvo gran éxito por parte de los usuarios ${ }^{61}$, y Dirk se convirtió en un personaje de culto (Jiménez, 2009: 556). Otros títulos que le siguieron fueron Dragon Slayer (Nihon Falcom, 1984)62, King's Quest I: Quest for the Crown (Sierra On-Line, 1984), Knight Lore (Ultimate Play The Game, 1984)63, The Lords of Midnight (Mike Singleton, 1984)64, o Barbarian: The Ultimate Warrior (Palace Software, 1987). Por dejar constancia de otras obras desarrolladas fuera de España ${ }^{65}$ hasta 1992, cuyo volumen impide ser citadas en su totalidad en el presente texto, se señalarán algunas de las más representativas, como fue el caso de la mitología irlandesa de Tir Na Nog (Gargoyle Games, 1984), el satanismo medieval de Underwurlde (Ultimate Play The Game, 1984), la brujería de Cauldron (Palace Software, 1985), la fantasía épica de Gauntlet (Atari, 1985), las aventuras del caballero Sir Arthur en Ghosts 'n Goblins (Capcom, 1985), el vampirismo medieval de Castlevania (Konami, 1986), la temprana estrategia de Defender of the Crown (Cinemaware, 1986), los inicios de las populares sagas de The Legend of Zelda (Nintendo, 1986) y Final Fantasy I-IV (Squaresoft, 1987-1991), los mundos tolkienianos de War in Middle Earth (Melbourne House, 1988), la espada y brujería de Golden Axe (Sega, 1989), los peligros de la medina islámica de Prince of Persia (Brøderbund, 1989) (Fig. 5), el arcade de Magic Sword (Capcom, 1990), las tácticas territoriales de Kingdom Crusade (Sculptured Software, 1991) y Sid Meier's Civilization (MicroProse, 1991), o las invasiones de orcos de Realms of Arkania: Blade of Destiny (Attic Entertainment, 1992). Como el listado podría continuar, sirvan de ejemplo los títulos citados para reconocer la influencia del Medievo y la fantasía épica en obras y sagas internacionales que han llegado hasta la actualidad a través de secuelas, remakes, adaptaciones, etc.

59 Desarrollado, a su vez, a raíz del éxito de Dungeons \& Dragons (Kushner, 2018: 19-20).

$60 \mathrm{Se}$ conoce como huevo de pascua al contenido secreto que puede haber en un producto digital. El caso de Adventure (Atari, 1979) formó parte de la trama de la novela Ready Player One (Cline, 2011), trasladada al cine en 2018 en la película homónima dirigida por Steven Spielberg.

61 Su interfaz pretendía emular una película interactiva, alejándose del píxel o los polígonos, adaptando en formato audiovisual los libros de escoge tu propia aventura, dando lugar a otros títulos como Thayer's Quest (RDI Video Systems, 1984), también de fantasía épica (Altozano, 2017: 186-187).

62 Uno de los primeros videojuegos de rol, o CRPG (Computer Role Playing Game) (Pepe, 2018: 491).

63 También tuvo muy buena acogida y popularizó la perspectiva isométrica (Esteve, 2012b: 417).

64 Obra referente del rol y la estrategia en la que se maximizó su potencial técnico, recreando multitud de entornos gráficos (Martínez del Vas et al., 2017: 180-181).

65 Algunos de estos títulos, como War in Middle Earth (Melbourne House, 1988), tuvieron conversiones entre formatos gracias a desarrolladoras españolas (Relinque \& Fernández, 2015: 351-353). 


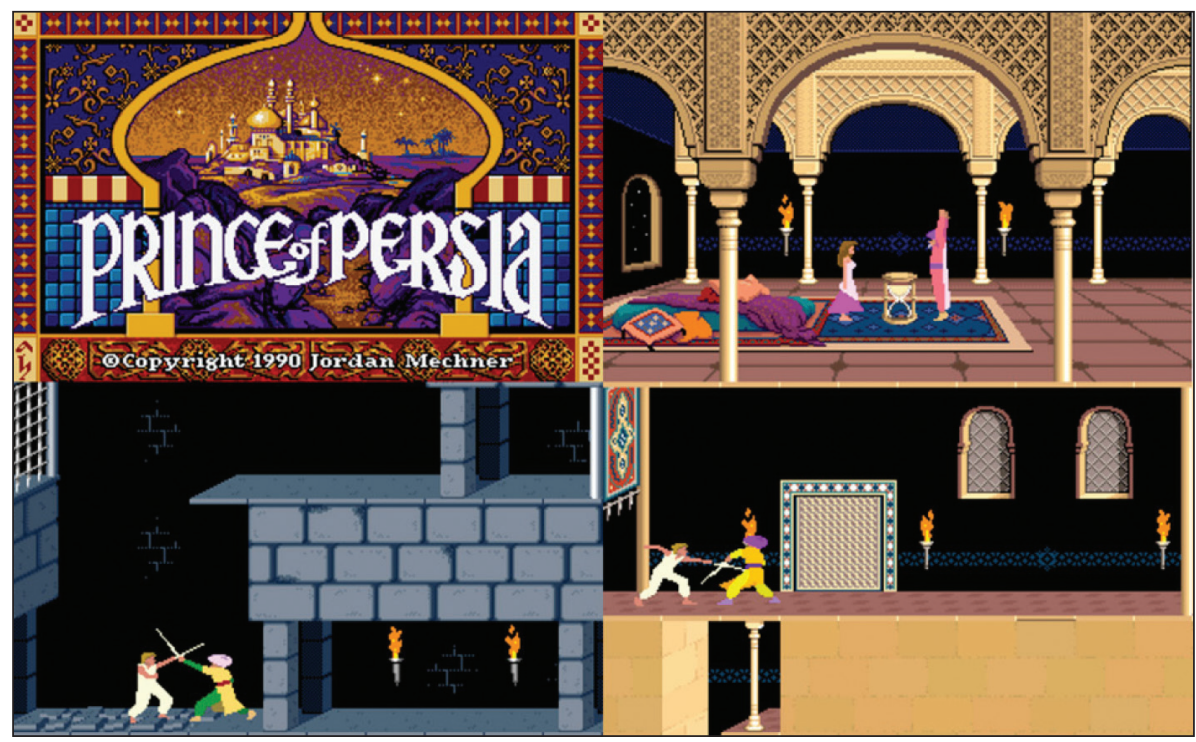

Figura 5: Imágenes de Prince of Persia (Brøderbund, 1989). Fuente: <https://funnyjunk.com/channel/vidyagaems/> [consulta: 17 abril 2018].

\section{CONCLUSIONES}

Tras la compilación realizada, nos encontramos ante una cifra de setenta y dos títulos ${ }^{66}$ que se desarrollaron en España, desde 1984 hasta 1992, bajo el paradigma medieval, especialmente a través de la mirada hacia «otro lugar» positivo. Además, en aquel temprano período aparecieron más de trescientos videojuegos españoles de temáticas variadas ${ }^{67}$. Cabe colegir que durante la Edad de Oro se demostró un destacado interés por la Edad Media, abarcando un porcentaje notorio de títulos en base a la producción total. Por ende, el apogeo y declive de la edad dorada también se refleja a través de la producción de software medieval a lo largo de aquellos años, siendo su cenit durante el trienio 1986-1988 (Fig. 6).

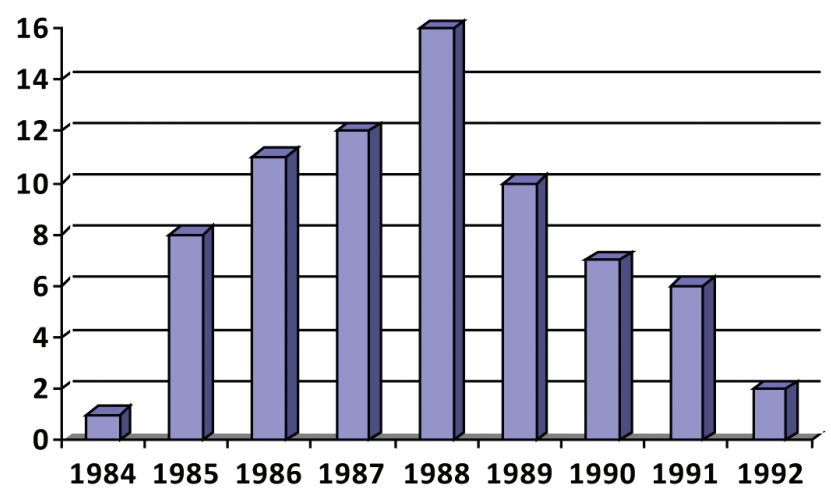

$\square$ Software español de temática medieval.

Figura 6: Videojuegos de temática medieval desarrollados en España de 1984 a 1992. Fuente: Elaboración propia.

66 Bajo la selección de los más representativos.

67 Mediante desarrolladoras más relevantes o a través de circuitos menos oficiales (Relinque \& Fernández, 2015). 
El año de mayor favorecimiento fue 1988, contando con dieciséis videojuegos medievales, con títulos como Arkos (Zigurat, 1988) o Hundra (Dinamic, 1988). A continuación le siguieron 1987 y 1986, con un desarrollo de doce y once videojuegos cada año, respectivamente, entre los que encontramos obras como Sir Fred (Made in Spain, 1986), Don Quijote (Dinamic, 1987) o Sir Camelot (Sygran, 1987). También cabe destacar que en aquellos meses salió a la venta La Abadía del Crimen (Opera Soft, 1987), considerado el videojuego más importante de la edad dorada. El declive queda reflejado a partir de 1990, con un desarrollo de siete videojuegos medievales, hasta el ocaso en 1992, cerrándose el broche de la Edad de Oro, en un sentido general, con Risky Woods (Dinamic \& Zeus Software, 1992) en particular, un título, precisamente, de fantasía épica. También cabe considerar que si se hubiesen tenido en cuenta únicamente los títulos de las desarrolladoras más oficiales, las cifras serían más exiguas, sobre todo a partir de 1990. Desde una perspectiva inductiva, se puede atisbar un auge y ocaso en el desarrollo de videojuegos españoles que, desde lo particular del Medievo se puede extrapolar a lo general en cuanto a la cantidad de títulos publicados durante aquellos años. Se trata de un fenómeno cuya impronta ha quedado patente en el mercado interno, en el que la falta de adaptación a los avances tecnológicos, junto a una economía e industrialización incapaces de competir con el mercado externo, dio lugar a una etapa de decadencia y crisis de la que bien podrían verse reflejadas otras industrias culturales españolas, como el cómic o el cine.

La fascinación por la Edad Media precede a la aparición de los primeros softwares de entretenimiento, los cuales han evolucionado desde sus primeros títulos de arcade o videoaventuras a la estrategia o al rol, derivados a su vez de los juegos de mesa, y cuyo trasvase se disfruta actualmente a través de los CRPG, los MMORPG ${ }^{68}$, y todo tipo de subgéneros. El interés por aquel período histórico, tan visitado en las distintas corrientes artísticas, permite conectar actualmente a los usuarios que demandan productos medievales en un sentido didáctico, aunque no necesariamente por parte del medievalista o del historiador profesional, sino también por el jugador casual o habitual de videojuegos. Por ello, el factor educativo en el espacio lúdico ha evolucionado juntamente con el propio desarrollo tecnológico, y es conveniente instar a que se reconozca definitivamente al videojuego, no únicamente como arte, sino también como herramienta pedagógica. Del mismo modo, la fantasía épica ha fascinado al usuario, tanto en un sentido estético como argumental, con anterioridad a la aparición de los primeros videojuegos. Se trata de un discurso cuyos personajes, tipología armamentística, arquitectura y leyendas forman los ingredientes necesarios para asegurar una experiencia lúdica que cumpla, en mayor o menor medida, las expectativas del usuario. En consecuencia, y como se puede observar en el mercado actual, el trasvase al píxel de la Edad Media como "otro lugar» positivo se manifiesta de manera afín al de la mirada medieval como sustrato histórico de verosimilitud o veracidad.

El legado posterior a la Edad de Oro del software español está empezando a acentuarse. Incluso la prensa especializada ha señalado que España podría estar viviendo, desde hace varios años, una segunda edad dorada ${ }^{69}$. Tras aquella etapa, en España aparecieron posteriormente títulos circunscritos al Medievo de un modo persistente y bajo nuevas

68 Acrónimo de Massively Multiplayer Online Role-Playing Games, videojuegos de rol multijugador masivos en línea, los cuales conectan a multitud de usuarios simultáneamente a través de internet.

69 Según la prensa especializada, en el año 2015 se podría haber iniciado una segunda Edad de Oro del software español (Alcolea, 2015). 
desarrolladoras, como fue el caso, por ejemplo, de Blade: The Edge of Darkness (Rebel Act Studios, 2001), Medievol: The Browser Game (Integra Media, 2007), The Abbey (Alcachofa Soft, 2008)70, Gommy, Defensor Medieval (Retroworks, 2009), Castlevania: Lords of Shadow (MercurySteam, 2010), Unepic (Ninagamers, 2011), Maldita Castilla (Locomalito, 2012), Los Amores de Brunilda (Retroworks, 2013), Ziggurat (Milkstone Studios, 2014), Vade Retro (Retroworks, 2015), King Lucas (DevilishGames, 2016), Become a Legend: Dungeon Quest (Inverge Studios, 2017), El Linaje Real (ESP Soft, 2017), The Sword of lanna (Retroworks, 2017), o Moonlighter (Digital Sun Games, 2018). Se trata de videojuegos españoles que, tras su salida al mercado, han competido al mismo nivel que otros títulos extranjeros en un ámbito internacional. Por ello, es necesario dar visibilidad al software español que existe actualmente, siendo conscientes de los orígenes y del camino que se está construyendo, para no tener que recordar en un futuro, y bajo una nueva mirada nostálgica, aquella segunda edad dorada que formó parte de otro tiempo mejor. En definitiva, hubo un período en el que España fue una de las principales potencias en el desarrollo de videojuegos, básicamente cuando éstos se encontraban en su génesis. Y aquella época abrió un camino sinuoso que es conveniente aderezar con el sustrato más competitivo, pues en éste seguirán resonando, bajo una u otra mirada, los ecos de la Edad Media.

\section{BIBLIOGRAFÍA CITADA}

Alcolea, A., «2015: ¿Comienza la segunda edad de oro del software español?», Hobby Consolas, 30 de diciembre de 2015; <https://www.hobbyconsolas.com/industria/2015comienza-segunda-edad-oro-software-espanol-603> [consulta: 17 abril 2018].

Alonso, A., "Los mejores juegos españoles de todos los tiempos», Hobby Consolas, 24 de abril de 2017; <https://www.hobbyconsolas.com/reportajes/mejores-juegos-espanolestodos-tiempos-62880> [consulta: 17 abril 2018].

Altozano, J., El videojuego a través de David Cage, Sevilla, Héroes de Papel, 2017.

Asadi, A. (dir.), The ZX Spectrum Book, Reino Unido, Imagine Publishing, 2015.

Avellaneda, E., «La Abadía del Crimen, primer título español que logró prestigio internacional», El País, 12 de septiembre de 2002; <https://elpais.com/diario/2002/09/12/ ciberpais/1031796144_850215.html> [consulta: 17 abril 2018].

Cline, E., Ready Player One, Barcelona, Ediciones B, 2011.

Crespo, A., 150 videojuegos a los que tienes que jugar al menos una vez en la vida, Madrid, Martínez Roca, 2010.

Eco, U., [1980], El Nombre de la Rosa, Barcelona, Lumen, 2005.

- Baudolino, Barcelona, Lumen, 2000.

Esteve, J. (coord.), Ocho Quilates, una historia de la edad de oro del software español (I), Barcelona, Ocho Quilates, 2012a.

- (coord.), Ocho Quilates, una historia de la edad de oro del software español (II). Barcelona, Ocho Quilates, 2012b

- (coord.), Obsequium. Un relato cultural, tecnológico y emocional de La Abadía del Crimen, Barcelona, Ocho Quilates, 2014.

70 Al igual que sucedió con La Abadía del Crimen (Opera Soft, 1987), fue otra adaptación no oficial, en formato de aventura a gráfica, de la novela de Umberto Eco (Esteve, 2014:117). 
Jiménez Alcázar, J. F., «Videojuegos y Edad Media», Imago Temporis. Medium Aevum, 3 (2009), pp. 551-587.

Kushner, D., Maestros del Doom: cómo dos colegas crearon un imperio y transformaron la cultura popular, Madrid, Es Pop Ediciones, 2018.

Martínez del Vas, J., et al., El Mundo del Spectrum +, Palma de Mallorca, Dolmen Editorial, 2017.

Pepe, F. (ed.), The CRPG Book Project. Sharing the History of Computer Role-Playing Games, Tokio, Felipe Pepe (Goodreads Author), 2018.

Perles, O., "La No Edad de Oro del Software Español», en Commodore Spain, 18 de agosto de 2015; <https://www.commodorespain.es/la-no-edad-de-oro-del-software-espanol/> [consulta: 17 abril 2018].

Portalo, F. \& Mena, E., «Los videojuegos como paradigma de innovación en los orígenes de la industria del software español», Novática. Revista de la Asociación de Técnicos de Informática, 231 (2015), pp. 99-106.

Portalo, F., Bugaboo, un hito en la Historia del Software Español, Cáceres, Universidad de Extremadura, Servicio de Publicaciones, 2009.

Relinque, J. \& Fernández, J. M., Génesis: Guía esencial de los videojuegos españoles de 8bits, Sevilla, Héroes de Papel, 2015.

Rollings, A., ZX Spectrum Book - 1982 to 199x, USA, Hiive Books, 2006.

Sajna, M., "Quasi-medieval register in video games - a translator's perspective», SKASE Journal of Translation and Interpretation, 1 (2016), pp. 44-50.

Segura, C., "Medievalistas enganchados a los videojuegos», El País, 13 de abril de 2017; $<$ https://elpais.com/ccaa/2017/04/12/catalunya/1492014219_875650.html> [consulta: 17 abril 2018].

Sergi, G., La idea de Edad Media, Barcelona, Crítica, 2001.

Tato, G., Una partida más y me acuesto. Los videojuegos de nuestras vidas: casetes, recreativas, joysticks y mucha nocilla, Barcelona, Minotauro, 2016.

Van der Heide, M. (dir.), World of Spectrum, 1995; <http://www.worldofspectrum.org/> [consulta: 17 abril 2018].

Veiga Sierra, J. L. (dir.), Computer Emuzone, 1999; <http://computeremuzone.com/> [consulta: 17 abril 2018].

Wilkins, C., The History of ZX Spectrum in Pixels, Reino Unido, Fusion Retro Books, 2014.

\section{LUDOGRAFÍA CITADA}

Abracadabra (Proein Soft Line, 1988).

Abu Simbel, Profanation (Dinamic Software, 1985).

Adventure (Atari, 1979).

Akbarr (Ardent Software, 1991).

Ambush (Tecfri, 1983).

Arkos (Zigurat, 1988).

Atrog (Zafiro Software, 1988).

Barbarian: The Ultimate Warrior (Palace Software, 1987).

Become a Legend: Dungeon Quest (Inverge Studios, 2017).

Blade: The Edge of Darkness (Rebel Act Studios, 2001).

Bugaboo / La Pulga (Indescomp, 1983). 
Camelot Warriors (Dinamic, 1985).

Castlevania (Konami, 1986).

Castlevania: Lords of Shadow (MercurySteam, 2010).

Cauldron (Palace Software, 1985).

Colossal Cave Adventure (William Crowther \& Don Woods, 1976).

Crusader (System 4, 1988).

Dea Tenebrarum (System 4, 1988).

Defender of the Crown (Cinemaware, 1986).

Don Quijote (Dinamic, 1987).

Drácula (GTS \& Génesis, 1986).

Dragon Slayer (Nihon Falcom, 1984).

Dragon's Lair (Advanced Microcomputer Systems, 1983).

Drakkar (Delta Software \& Diabolic, 1989).

Dungeons \& Dragons (Gary Whisenhunt \& Ray Wood, 1975).

El Capitán Trueno (Dinamic, 1989).

El Castillo de Godless (Idealogic, 1985).

El Castillo Embrujado (Microhobby, 1986).

El Cid (Dro Soft \& Juliet Software, 1987).

El Cruzado (Nuevo Soft Español, 1987).

El Descubrimiento de América (OMK Software, 1986).

El Linaje Real (ESP Soft, 2017).

El Señor de los Anillos (Dimassoft, 1991).

El Señor del Dragón (Creators Union, 1989).

Elidon (Orpheus, 1985).

Enchanted (Positive, 1989).

Excalibur (Q.L.S., 1985).

Final Fantasy I-IV (Squaresoft, 1987-1991).

Fred (Indescomp, 1983).

Fredy (GTS, 1987).

Gauntlet (Atari, 1985).

Genghis Khan (Positive, 1991).

Ghosts 'n Goblins (Capcom, 1985).

Golden Axe (Sega, 1989).

Gommy, Defensor Medieval (Retroworks, 2009).

Gorbaf el Vikingo (Magic Team, 1987).

Guillem de Berguedá (ACE Software, 1985).

Guillermo Idiliar Dambor (Creators Union, 1991).

Guillermo Tell (Opera Soft, 1989).

Historias de Medialand (JSJ Soft, 1987).

Hundra (Dinamic, 1988).

Khazzad-Dum (System 4, 1989).

King Leonard (Mind Games, 1986).

King Lucas (DevilishGames, 2016).

Kingdom Crusade (Sculptured Software, 1991).

King's Quest I: Quest for the Crown (Sierra On-Line, 1984).

Knight Ghost (Juliet Software, 1987). 
Knight Lore (Ultimate Play The Game, 1984).

Krom: El Guerrero Invencible (OMK Software, 1989).

La Abadía del Crimen (Opera Soft, 1987).

La Aventura Original (Aventuras AD, 1989).

La Corona (System 4, 1988).

La Corona Mágica (OMK Software, 1990).

La Cueva del Dragón (Manali, 1990).

La Espada Sagrada (Topo Soft, 1990).

La Liberación de Silvania (Aventuras FJAP, 1991).

La Maldición de Jarak (Sygran, 1986).

La Princesa (Software Center, 1985).

Las Tres Luces de Glaurung (Erbe Software, 1986).

Legend (Delta Software, 1990).

Leyendas (Mind Games, 1988).

Livingstone Supongo (Opera Soft, 1986).

Lorna (Topo Soft, 1990).

Los Amores de Brunilda (Retroworks, 2013).

Magic Sword (Capcom, 1990).

Maldita Castilla (Locomalito, 2012).

Medievol: The Browser Game (Integra Media, 2007).

Mega Chess (Genesis Soft, 1988).

Merlin (Mind Games, 1987).

Mithos (Opera Soft, 1990).

Moonlighter (Digital Sun Games, 2018).

Nonamed (Dinamic, 1986).

Power Magic (Zigurat, 1990).

Prince of Persia (Brøderbund, 1989).

Pueblo de la Noche (Creators Union, 1989).

Realms of Arkania: Blade of Destiny (Attic Entertainment, 1992).

Risky Woods (Dinamic \& Zeus Software, 1992).

Robin (Indescomp, 1986).

Rocman (Magic Team, 1986).

Satan (Dinamic, 1989).

Sgrizam (Dinamic, 1985).

Sid Meier's Civilization (MicroProse, 1991).

Silphy (lber Software, 1988).

Sir Camelot (Sygran, 1987).

Sir Fred (Made in Spain, 1986).

Sir Lancelot / Sir Perceval (OMK Software, 1985).

Sirwood (Opera Soft, 1990).

Spirits (Topo Soft, 1987).

Starlife (Zafiro Software, 1988).

Super Chess (Kuma Computers, 1984).

Talismán (Unicornio Soft \& A.G.D., 1987).

Temptations (Topo Soft, 1988).

Thanos (Microhobby, 1988). 
Thayer's Quest (RDI Video Systems, 1984).

The Abbey (Alcachofa Soft, 2008).

The Last Warrior (Iron Chip, 1991).

The Legend of Zelda (Nintendo, 1986).

The Lords of Midnight (Mike Singleton, 1984).

The Prayer of the Warrior (Zigurat, 1992).

The Sword of lanna (Retroworks, 2017).

Thor (Proein Soft Line, 1988).

Thor y la Cría de Dragón (GTS, 1986).

Tir Na Nog (Gargoyle Games, 1984).

Tuareg (Topo Soft, 1988).

Ultima I: The First Age of Darkness (Richard Garriott, 1981).

Underwurlde (Ultimate Play The Game, 1984).

Unepic (Ninagamers, 2011).

Vade Retro (Retroworks, 2015).

War in Middle Earth (Melbourne House, 1988).

Wizardry: Proving Grounds of the Mad Overlord (Sir-Tech, 1981).

Yenght: La Fuente de la Juventud (Dinamic, 1984).

Zhak (Microhobby \& Legio Soft, 1988).

Ziggurat (Milkstone Studios, 2014).

Quaderns, 13 (2018), pp. 63-84 